Article

\title{
Brain-Specific Serine-47 Modification of Cytochrome $c$ Regulates Cytochrome $c$ Oxidase Activity Attenuating ROS Production and Cell Death: Implications for Ischemia/Reperfusion Injury and Akt Signaling
}

\author{
Hasini A. Kalpage ${ }^{1}$, Junmei Wan ${ }^{1}$, Paul T. Morse ${ }^{1}{ }^{\circledR}$, Icksoo Lee ${ }^{2}$ and Maik Hüttemann ${ }^{1,3, *}$ \\ 1 Center for Molecular Medicine and Genetics, Wayne State University, Detroit, MI 48201, USA; \\ hkalpage@med.wayne.edu (H.A.K.); am4472@wayne.edu (J.W.); morsepa@wayne.edu (P.T.M.) \\ 2 College of Medicine, Dankook University, Cheonan-si, Chungcheongnam-do 31116, Korea; \\ icksoolee@dankook.ac.kr \\ 3 Department of Biochemistry, Microbiology and Immunology, Wayne State University, Detroit, MI 48201, USA \\ * Correspondence: mhuttema@med.wayne.edu; Tel.: +1-313-577-9150; Fax: +1-313-577-5218
}

Received: 17 May 2020; Accepted: 3 August 2020; Published: 6 August 2020

\begin{abstract}
We previously reported that serine-47 (S47) phosphorylation of cytochrome $c$ (Cytc) in the brain results in lower cytochrome $c$ oxidase (COX) activity and caspase-3 activity in vitro. We here analyze the effect of $S 47$ modification in fibroblast cell lines stably expressing S47E phosphomimetic Cytc, unphosphorylated WT, or S47A Cytc. Our results show that S47E Cytc results in partial inhibition of mitochondrial respiration corresponding with lower mitochondrial membrane potentials $\left(\Delta \Psi_{\mathrm{m}}\right)$ and reduced reactive oxygen species (ROS) production. When exposed to an oxygen-glucose deprivation/reoxygenation (OGD/R) model simulating ischemia/reperfusion injury, the Cytc S47E phosphomimetic cell line showed minimal ROS generation compared to the unphosphorylated WT Cytc cell line that generated high levels of ROS upon reoxygenation. Consequently, the S47E Cytc cell line also resulted in significantly lower cell death upon exposure to OGD/R, confirming the cytoprotective role of S47 phosphorylation of Cytc. S47E Cytc also resulted in lower cell death upon $\mathrm{H}_{2} \mathrm{O}_{2}$ treatment. Finally, we propose that pro-survival kinase Akt (protein kinase B) is a likely mediator of the S47 phosphorylation of Cytc in the brain. Akt inhibitor wortmannin abolished S47 phosphorylation of Cytc, while the Akt activator SC79 maintained S47 phosphorylation of Cytc. Overall, our results suggest that loss of $S 47$ phosphorylation of Cytc during brain ischemia drives reperfusion injury through maximal electron transport chain flux, $\Delta \Psi_{\mathrm{m}}$ hyperpolarization, and ROS-triggered cell death.
\end{abstract}

Keywords: cytochrome $c$; phosphorylation; ischemia/reperfusion injury; cell signaling; apoptosis; electron transport chain; brain; reactive oxygen species; mitochondrial membrane potential

\section{Introduction}

Cytochrome $c(\mathrm{Cyt} c)$ is a small, 104 amino acid protein, with a covalently attached heme group. It functions at the intersection between cellular respiration and intrinsic apoptosis, linking the two pathways. Cytc plays a role in cellular respiration by functioning as the electron carrier between complex III and complex IV (cytochrome $c$ oxidase, COX) in the mitochondrial electron transport chain (ETC) [1,2]. In contrast, the release of Cytc from the mitochondria into the cytosol is considered the committing step for intrinsic apoptosis. Cytc acts as a trigger of apoptosis by interacting with apoptosis protease activating factor-1 (Apaf-1) to form the apoptosome, which activates caspase- 9 to initiate the caspase cascade, the executioner pathway of intrinsic apoptosis $[3,4]$. Cytc serves as a key 
metabolic regulator and orchestrator of cellular life and death decisions. In addition to respiration and apoptosis, Cytc has multiple other cellular functions, such as reactive oxygen species (ROS) scavenging, cardiolipin peroxidase activity, redox-coupled protein import, and ROS formation via the p66Shc protein $[1,5]$. The COX-catalyzed electron transfer from Cytc to oxygen is the proposed rate-limiting step of the ETC $[2,6,7]$. Therefore, the functions of Cytc are tightly regulated by all major regulatory mechanisms, such as allosteric regulation by ATP, expression of tissue-specific isoforms, and reversible post-translational modifications (PTMs), of which phosphorylations are physiologically most relevant [5].

So far, five tissue-specific phosphorylations have been mapped on mammalian Cytc—Y97 [8,9], Y48 [10], T28 [11], S47 [12], and T58 [13]. These modifications strongly impact the functions of the protein, including respiration, apoptosis, cardiolipin peroxidase activity, and ROS scavenging capability $[11,13,14]$. We recently showed that S47 phosphorylation is the basal PTM found in the mammalian brain. This phosphorylation was found in $30 \%$ of the Cytc pool, making it a biologically significant modification. Furthermore, this phosphorylation was found to be completely lost under ischemia, implying a critical role for this modification in the brain under healthy basal conditions. Our initial study used in vivo phosphorylated and S47E phosphomimetic Cytc for the in vitro functional characterization with consistent results between the two systems, demonstrating that our phosphomimetic replacement serves as a good model. We reported that brain COX activity was reduced by $54.3 \%$, caspase- 3 activity was reduced by $64.5 \%$, and cardiolipin peroxidase activity was reduced by about $50 \%$ in the presence of the S47 phosphomimetic S47E compared to unphosphorylated WT Cytc [12]. These experiments were performed in a cell-free in vitro system using purified recombinant proteins. Given the pathological relevance of this modification under ischemia, a condition observed in stroke and global brain ischemia following cardiac arrest, we further extended characterization of S47 phosphorylation into a live cell culture model with exposure to oxygen-glucose deprivation/reoxygenation (OGD/R) mimicking ischemia/reperfusion injury that takes place as a result of stroke [15].

Globally, strokes are the second leading cause of death and the third leading cause of disability [16]. Most strokes are ischemic in origin, where blood flow to the brain is disrupted by occlusion of a blood vessel. Restoration of blood flow further damages the ischemic core and surrounding tissue called the penumbra as a result of reperfusion injury, exacerbating the stroke pathology [17]. ROS are implicated in reperfusion injury [18], and since the mitochondrial ETC is the primary source of cellular ROS, the ETC thus plays an important role in ischemia/reperfusion injury [19]. We propose that the regulatory functions of $S 47$ phosphorylation of Cytc, which are lost during ischemia, play a central role in brain ischemia/reperfusion injury through the following mechanism: Under ischemic stress calcium builds up in the mitochondria, leading to dephosphorylation of Cytc and other ETC proteins. This causes hyperactivation of the mitochondrial ETC during reperfusion when oxygen becomes available again, resulting in pathologically high mitochondrial membrane potentials $\left(\Delta \Psi_{\mathrm{m}}\right)$. In turn, this triggers an exponential increase in the generation of ROS, which causes further tissue damage and initiates cell death cascades [17]. Our data support the concept that cell death due to ischemia/reperfusion injury takes place via a Cytc-centered mechanism mediated by loss of its phosphorylations. Furthermore, we propose that S47 phosphorylation is likely mediated by the pro-survival kinase Akt under normal conditions.

\section{Materials and Methods}

\subsection{Cell Culture and Stable Transfection of Cytc Constructs}

WT Cytc cloned into pBABE-puro expression plasmid (Addgene, Cambridge, MA, USA) was used to generate S47A and S47E Cytc variants using site-directed mutagenesis (Agilent Technologies, Santa Clara, CA, USA), as previously described [12], with the following mutagenesis oligonucleotides: S47E forward primer: 5'-CCAGGCTGCTGGATTCGAGTACACAGATGCC-3', S47E reverse primer: 5'-GGCATCTGTGTACTCGAATCCAGCAGCCTGG-3', S47A forward primer: 
5'-CCAGGCTGCTGGATTCGCTTACACAGATGCC-3', S47A reverse primer: 5' -GGCATCTGTGTAA GCGAATCCAGCAGCCTGG-3'. WT, S47E, and S47A Cytc expression constructs were stably transfected into Cytc double-knockout mouse lung fibroblasts (a kind gift from Dr. Carlos Moraes, University of Miami, Coral Gables, FL, USA) using Transfast transfection reagent (Promega, Madison, WI, USA) in a 1:1 transfection reagent to DNA ratio, as described in the manufacturer's protocol. The transfected cells were cultured in DMEM supplemented with 10\% FBS (Sigma-Aldrich, St. Louis, MO, USA), $100 \mu \mathrm{g} / \mathrm{mL}$ primocin (Invivogen, San Diego, CA, USA), $1 \mathrm{mM}$ sodium pyruvate, and $50 \mathrm{mg} / \mathrm{mL}$ uridine in selection media with $3 \mu \mathrm{g} / \mathrm{mL}$ puromycin at $37{ }^{\circ} \mathrm{C}$ in $5 \% \mathrm{CO}_{2}$.

\subsection{Gel Electrophoresis and Western Blotting}

Cytc expression in stably-transfected Cytc double-knockout mouse lung fibroblasts was confirmed with a mouse Cytc antibody (BD pharmingen, San Jose, CA, USA, \#556433) used at a 1:1000 dilution in $5 \%$ dry milk. Briefly, cells were lysed in RIPA lysis buffer supplemented with protease inhibitor cocktail (Sigma-Aldrich). The cellular protein lysates were quantified using the DC protein assay (Bio-Rad, Hercules, CA, USA) based on the Lowry method. Thirty micrograms of total cell lysate of each cell line were run on a $10 \%$ tris-tricine SDS-PAGE gel in the presence of anode ( $200 \mathrm{mM}$ Tris, $\mathrm{pH}$ 8.9) and cathode buffers (100 mM Tris, $100 \mathrm{mM}$ Tricine, $0.1 \%$ SDS, $\mathrm{pH}$ 8.25). The gel was transferred onto a PVDF membrane (Bio-Rad) using a semi-dry apparatus (Bio-Rad) and incubated with the primary antibody overnight at $4{ }^{\circ} \mathrm{C}$. The same lysates were also probed for subunits of the ETC complexes with the following antibodies at a dilution of 1:1000: NDUFB6 (NADH:Ubiquinone Oxidoreductase Subunit B6) for complex I (Abcam, Cambridge, MA, USA \#ab110244), SDHA (Succinate Dehydrogenase Complex Flavoprotein Subunit A) for complex II (Abcam, \#ab14715), UQCRC1 (Ubiquinol-Cytochrome $c$ Reductase Core Protein 1) for complex III (Abcam, \#ab110252), COX4 (Cytochrome $c$ Oxidase Subunit 4) for complex IV (Proteintech, Rosemont, IL, USA, \#11242-1-AP), and ATP5A (ATP Synthase Subunit Alpha) for complex V (Abcam, \#ab110273). Cell lysates were also probed with a 4-hydroxynonenal monoclonal antibody (clone 12F7) (Thermoscientific, Waltham, MA, USA, \#MA5-27570). The blots were probed for tubulin (Proteintech, \#11224-1-AP) as a loading control. HRP-conjugated mouse and rabbit secondary antibodies (GE Healthcare, Chicago, IL, USA) were used at a 1:5000 dilution. The blots were visualized using the HyGLO chemiluminescent HRP detection reagent (Denville Scientific Inc, Metuchen, NJ, USA).

\subsection{Measurement of Oxygen Consumption and Extracellular Acidification Rate}

Cells were seeded at a density of 25,000/well in a gelatin-coated XF24 plate (Agilent, \#100777-004). After overnight incubation, the growth medium was replaced with $675 \mu \mathrm{L}$ of Seahorse media (\#D5030 DMEM) supplemented with $10 \mathrm{mM}$ galactose without FBS or phenol red. In independent experiments, the growth medium was also replaced with $675 \mu \mathrm{L}$ of seahorse media supplemented with $10 \mathrm{mM}$ sodium pyruvate and $10 \mathrm{mM}$ glucose. The cells were incubated in a $\mathrm{CO}_{2}$-free incubator for $1 \mathrm{~h}$, and the basal oxygen consumption rate (OCR) was measured, followed by mitochondrial stress test with sequential injections of oligomycin $(1 \mu \mathrm{M})$, trifluoromethoxy carbonylcyanide phenylhydrazone (FCCP, $0.5 \mu \mathrm{M})$, and rotenone/antimycin $\mathrm{A}(1 \mu \mathrm{M})$ in an XFe24 Seahorse bioanalyzer (Seahorse Biosciences, North Billerica, MA, USA), according to the manufacturer's protocol. Extracellular acidification rate (ECAR) was determined as a measure of the rate of glycolysis in Seahorse medium supplemented with $10 \mathrm{mM}$ sodium pyruvate and $10 \mathrm{mM}$ glucose.

\subsection{Measurement of Membrane Potential}

Mitochondrial membrane potential $\left(\Delta \Psi_{\mathrm{m}}\right)$ was measured using the ratiometric JC-1 (5, 5' , 6, $6^{\prime}$ tetrachloro-1,1',3,3'-tetraethylbenzimidazolylcarbocyanine iodide) probe (Invitrogen, Carlsbad, CA, USA, \#T3168). Cells were seeded (25,000 cells/well) in a black 96-well plate (Corning, \#CLS3603). The growth medium was changed into FBS-free, phenol red-free high glucose ( $4.5 \mathrm{~g} / \mathrm{L})$ DMEM cell culture medium supplemented with $0.5 \mu \mathrm{M} \mathrm{JC}-1$ and incubated for $30 \mathrm{~min}$. Cells were washed 
with $1 \times$ PBS twice. Green fluorescence (excitation $485 \mathrm{~nm} / \mathrm{emission} 527 \mathrm{~nm}$ ) and red fluorescence (excitation $485 \mathrm{~nm} / \mathrm{emission} 590 \mathrm{~nm}$ ) of the cells were measured using a Fluorskan Ascent FL plate reader (Thermoscientific). $\Delta \Psi_{\mathrm{m}}$ was represented as a ratio of red/green fluorescence. $\Delta \Psi_{\mathrm{m}}$ uncoupler FCCP $(1 \mu \mathrm{M})$ was used as a negative control.

\subsection{Measurement of Mitochondrial ROS Production}

Mitochondrial ROS production was measured using MitoSOX red mitochondrial superoxide indicator probe (Invitrogen, \#M36008). Cells were seeded (100,000 cells/well) on a 24-well plate and incubated in FBS-free, phenol red-free high glucose ( $4.5 \mathrm{~g} / \mathrm{L})$ DMEM cell culture medium supplemented with $5 \mu \mathrm{M}$ MitoSOX for $30 \mathrm{~min}$ at $37^{\circ} \mathrm{C}$. Cells were washed with $1 \times$ PBS. Fluorescence (excitation $510 \mathrm{~nm} / \mathrm{emission} 580 \mathrm{~nm}$ ) was measured using a Synergy H1 plate reader (BioTek, Winooski, VT, USA).

\subsection{Measurement of ATP Levels}

Cultured fibroblasts were collected by scraping. The pellets were immediately frozen in less than $90 \mathrm{~s}$ and stored at $-80^{\circ} \mathrm{C}$ until analysis. The samples were boiled in the presence of $300 \mu \mathrm{L}$ of boiling buffer (100 mM Tris-Cl, 4 mM EDTA, pH 7.75) and sonicated on ice. The sample lysates were diluted 300-fold. The ATP concentration of $40 \mu \mathrm{L}$ diluted lysate was measured using the ATP bioluminescence assay kit HS II (Roche, Indianapolis, IN, USA), according to the manufacturer's protocol, using an Optocomp 1 luminometer (MGM Instruments, Hamden, CT, USA). The results were normalized to the protein concentration determined using the DC protein assay kit (Bio-Rad).

\subsection{Oxygen-Glucose Deprivation/Reoxygenation (OGD/R) Experiments}

To model ischemia/reperfusion conditions, stable cell lines expressing Cytc variants were exposed to transient oxygen-glucose deprivation (OGD). Cells were seeded and cultured according to our standard protocol described above. The media was exchanged into glucose-free, FBS-free, phenol red-free DMEM (Gibco, \#A1443001) bubbled with $95 \% \mathrm{~N}_{2}$ and $5 \% \mathrm{CO}_{2}$ (ischemia-mimetic media). Cells were incubated in ischemia-mimetic media with a $1 \% \mathrm{O}_{2}$ and $5 \% \mathrm{CO}_{2}$ atmosphere in a hypoxic chamber under the control of ProOx 110 oxygen and $\mathrm{ProCO}_{2}$ carbon dioxide controllers (Biospehrix, Redfield, NY, USA) for $90 \mathrm{~min}$ at $37^{\circ} \mathrm{C}$ unless otherwise stated. After ischemia, cells were reoxygenated for 30 min with glucose-containing, FBS-free, phenol red-free DMEM culture medium (Gibco, \#31053028) supplemented with the respective probe.

\subsection{Measurement of Cell Death Using Annexin V/PI Staining}

Cells were exposed to OGD/R (12 h ischemia/1 h reperfusion), as previously described [20], or treated with $\mathrm{H}_{2} \mathrm{O}_{2}$ (400 $\mu \mathrm{M}$ for $16 \mathrm{~h}$ ). Cells were harvested, washed with cold $1 \times$ PBS twice, and resuspended in $1 \times$ annexin $\mathrm{V}$ binding buffer (0.1 M HEPES, pH 7.4, $1.4 \mathrm{M} \mathrm{NaCl}$, and $25 \mathrm{mM}$ $\mathrm{CaCl}_{2}$ ). A total of $1 \times 10^{6}$ cells were stained with annexin $\mathrm{V}$ and propidium iodide (PI), as described in the annexin V/PI staining apoptosis kit manual (BD biosciences, San Jose, CA, USA). The cells were resuspended in $1 \mathrm{~mL}$ of annexin $\mathrm{V}$ binding buffer, and the data were collected using a flow cytometer (FloMax, Sysmex America, Inc., Lincolnshire, IL, USA). The results were analyzed using FCS Express 7 software (De Novo Software, Glendale, CA, USA).

\subsection{Akt Kinase Assay}

Recombinant Akt 1 (\#A16-10G), Akt 2 (\#A17-10G), and Akt 3 (\#A18-10G) isoforms were purchased from SignalChem (Richmond, British Columbia, Canada). The in vitro kinase reaction was performed in $50 \mathrm{mM}$ HEPES (pH 7.5), $10 \mathrm{mM} \mathrm{MgCl}, 1 \mathrm{mM}$ EGTA, $200 \mu \mathrm{M}$ ATP, 0.01\% Brij-35 buffer with $2 \mu \mathrm{M}$ Cytc at $30^{\circ} \mathrm{C}$. The serine phosphorylation state of Cytc was determined by Western blotting at times 0,15 , and $30 \mathrm{~min}$. The blots were probed with a 1:5000 dilution of phosphoserine antibody 
(Millipore, Burlington, MA, USA \#AB1603) in 5\% BSA-TBST buffer, followed by a 1:10,000 dilution of HRP-conjugated rabbit secondary antibody (GE Healthcare).

\subsection{Tissue Treatment with Pharmacological Compounds and Cytochrome c Purification}

Freshly harvested pig brain tissue was thoroughly washed with ice-cold $1 \times$ PBS, cut into smaller pieces, and minced using a commercial meat grinder. All procedures involving animal tissues were approved by the Wayne State University Institutional Animal Care and Use Committee. The tissue was suspended in $250 \mathrm{mM}$ sucrose, $20 \mathrm{mM}$ Tris-Cl buffer supplemented with $10 \mathrm{mM}$ potassium fluoride (KF), $2 \mathrm{mM}$ ethylene glycol tetraacetic acid (EGTA), and $1 \mathrm{mM}$ Phenylmethylsulfonyl fluoride (PMSF). The tissue homogenate was divided into 3 equal volumes. The fractions were treated with $13.7 \mu \mathrm{M}$ SC79, an Akt activator (Sigma-Aldrich, \#SML0749,), $10 \mu \mathrm{M}$ wortmannin (Sigma-Aldrich, \#W1628), an inhibitor of the phosphoinositide 3-kinase (PI3K)/Akt pathway, or DMSO as solvent control. Tissues were incubated at $37^{\circ} \mathrm{C}$ for $30 \mathrm{~min}$ with stirring to allow adequate tissue respiration and oxygenation. The $\mathrm{pH}$ was adjusted to 7.5. Following treatment, brain Cytc was purified, as previously described [12].

\subsection{Mitochondrial Subfractionation}

Freshly harvested pig brain tissue was homogenized in $250 \mathrm{mM}$ sucrose, $20 \mathrm{mM}$ Tris-Cl buffer supplemented with $10 \mathrm{mM} \mathrm{KF}, 2 \mathrm{mM}$ EGTA, and $1 \mathrm{mM}$ PMSF. All procedures involving animal tissues were approved by the Wayne State University Institutional Animal Care and Use Committee. The homogenate was spun at $650 \times \mathrm{g}$ for $10 \mathrm{~min}$ to remove the tissue debris. The supernatant was filtered through a cheesecloth and spun at 14,000 $\mathrm{g}$ for $20 \mathrm{~min}$ to collect the mitochondria. The pellet was homogenized with a glass Dounce homogenizer and centrifuged at $300 \times g$ for $8 \mathrm{~min}$. The supernatant was again spun at $14,000 \times g$ for $20 \mathrm{~min}$ to collect the mitochondria. The pellet was resuspended in $10 \mathrm{mM}$ HEPES buffer ( $\mathrm{pH}$ 7.5) containing $210 \mathrm{mM}$ mannitol, $70 \mathrm{mM}$ sucrose, and $1 \mathrm{mM}$ EDTA. Mitochondrial protein content was quantified using the DC protein assay (Bio-Rad). Two sucrose solutions $(1.2 \mathrm{M}$ and $1.6 \mathrm{M})$ of varying density were prepared, and $16 \mathrm{~mL}$ of $1.6 \mathrm{M}$ sucrose solution was added to a Beckmann ultra-clear tube (\#344058), followed by $19 \mathrm{~mL}$ of $1.2 \mathrm{M}$ sucrose solution. Each sucrose gradient was loaded with $5 \mathrm{mg}$ of mitochondrial protein, and the tubes were spun at 27,000 rpm in a Beckmann SW28 swing rotor for $2 \mathrm{~h}$ at $4{ }^{\circ} \mathrm{C}$. The mitochondrial fraction was extracted from the tube using a $5 \mathrm{cc}$ syringe with an 18 gauge needle. The collected fraction was centrifuged at 50,000 rpm in a Beckmann type 75 Ti rotor. The pellet was resuspended in $250 \mathrm{mM}$ sucrose, $10 \mathrm{mM}$ Tris-Cl, and $20 \mathrm{mM}$ EDTA buffer ( $\mathrm{pH} 7.6$ ) and spun at 22,000× $g$ for $15 \mathrm{~min}$. The pellet was then resuspended in a hypertonic solution $(20 \mathrm{mM}$ sodium phosphate, $\mathrm{pH}$ $7.2,0.02 \% \mathrm{BSA}$ ) and allowed to swell for $20 \mathrm{~min}$ on ice, as previously described [11]. After $20 \mathrm{~min}$, $1 \mathrm{mM}$ ATP and $1 \mathrm{mM} \mathrm{MgCl}_{2}$ were added and further incubated for $5 \mathrm{~min}$. The suspension was centrifuged at $15,000 \times \mathrm{g}$ for $10 \mathrm{~min}$ at $4{ }^{\circ} \mathrm{C}$. The supernatant was collected as the mitochondrial IMS (intermembrane space) fraction, and the pellet was collected as a mixture of mitoplasts, OMM (outer mitochondrial membrane), IMM (inner mitochondrial membrane), and residual IMS. The fractions were immunoblotted with the following antibodies: pAkt (CST, Danvers, MA, USA, \#4060S), total-Akt (CST, \#C67E7), cytochrome $c$ (BD pharmingen, \#556433), COX4 (Proteintech, \#11242-1-AP), heat shock protein 60 (HSP60) (Proteintech, \#66041), and tubulin (Proteintech, \#11224-1-AP).

\subsection{Recombinant Cytc Purification and Cytc Oxidation by Hydrogen Peroxide}

WT, S47A, and S47E variants were overexpressed in C41(DE3) competent bacterial cells (Lucigen, Middleton, WI, USA) and purified using ion-exchange chromatography, as previously described [12]. WT, S47E, and S47A Cytc were fully reduced with sodium dithionite and desalted on a NAP5 column (GE Healthcare). The initial rate of Cytc oxidation with $100 \mu \mathrm{M} \mathrm{H}_{2} \mathrm{O}_{2}$ within the first $10 \mathrm{~s}$ was calculated, as previously described [13]. The rate of Cytc oxidation is represented as $\%$ of the WT. 


\subsection{Statistical Analyses}

Statistical analyses of the data were performed with MSTAT version 6.1 (University of Wisconsin, Madison, WI, USA) using the Wilcoxon rank-sum test. Data are reported as means \pm SEM with three or more replicates and were considered statistically significant $\left(^{*}\right)$ with $p<0.05$.

\section{Results}

\subsection{Overexpression of WT, S47A, and S47E Cytc in Cytc Double-Knockout Cells Restores Expression of Complex I, III, and IV}

To study the functional effects of S47E phosphomimetic substitution of Cytc in an intact cell culture system, we created cell lines stably expressing S47E Cytc, WT Cytc, and S47A Cytc as an additional control that cannot be phosphorylated. These Cytc variants were transfected into a Cytc double-knockout mouse lung fibroblast cell line where both the rodent testes and somatic isoforms of Cytc were knocked out [21]. Cell lines that were equally expressing WT, S47E, and S47A Cytc, along with a Cytc-null empty vector (EV) control, were used for the functional studies (Figure 1A). These cell lines were probed for subunits of the five complexes involved in oxidative phosphorylation (OxPhos). In the EV cell line, the protein expression levels of complex I subunit (NDUFB6), complex III subunit (UQCRC1), and complex IV subunit (COX4) were lower (Figure 1A). Consistent with previous studies [11], when Cytc was expressed in Cytc double-knockout cells, there was an upregulation of the ETC complexes involved in proton pumping, suggesting that reintroduced Cytc was integrated into the mitochondria, resulting in OxPhos competent cells.

\subsection{S47E Cytc Expression Results in Lower Mitochondrial Respiration and Higher Glycolysis Rates}

Intact cell oxygen consumption rate of the four cell lines was measured using a Seahorse bioanalyzer. There was a 59\% decrease and a 52\% decrease in intact cell oxygen consumption rate (OCR) in the S47E phosphomimetic Cytc cell line as compared to WT Cytc cell line cultured in $10 \mathrm{mM}$ galactose supplemented media (Figure 1B, Figure S1B) and $10 \mathrm{mM}$ glucose and $10 \mathrm{mM}$ sodium pyruvate supplemented media (Figure S2B), respectively. This was similar to the difference in OCR that was observed in the in vitro reaction of purified S47-phosphorylated Cytc with purified COX analyzed in an oxygen electrode chamber [12]. The S47E cell line also resulted in lower respiration due to decreased proton leak and lower ATP-coupled respiration after the addition of oligomycin during the mitochondrial stress test (Figures S1A,C,D and S2A,C,D). The rate of glycolysis of these cells was determined indirectly by measurement of the extracellular acidification rate (ECAR). Extracellular measurement of lactic acid production is considered to be a reasonable estimate of glycolytic flux [22]. The rate of glycolysis showed a behavior opposite to that of OCR (Figure 1C, Figure S3A). The S47E cell line resulted in a significantly higher rate of extracellular acidification compared to the WT and S47A cell lines, suggesting an adaptation in cellular bioenergetics to compensate for the decrease in oxygen consumption. The Cytc-null EV cell line, which is OxPhos deficient, resulted in the highest rate of glycolysis, representing a complete metabolic switch to glycolysis. 
A

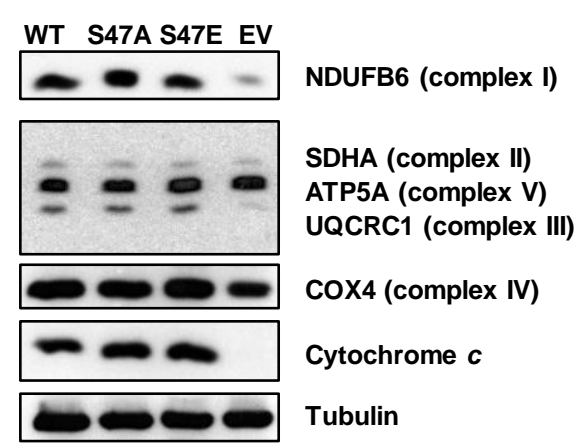

B

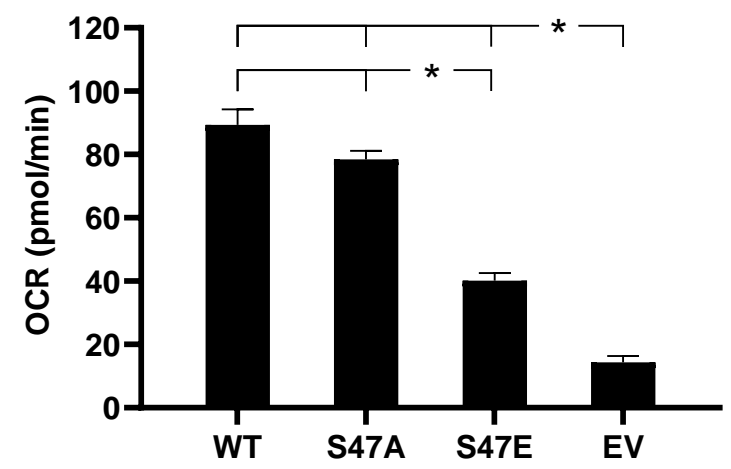

C

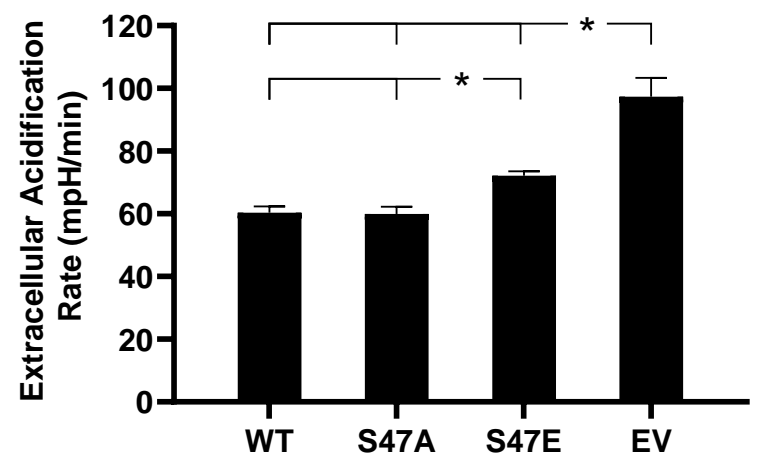

Figure 1. (A) Cytochrome c (Cytc) double-knockout cells stably transfected with empty vector (EV) and wild type (WT), S47A, S47E Cytc expression constructs were immunoprobed for Cytc, together with loading control tubulin, and OxPhos complex subunits NDUFB6 (complex I), SDHA (complex II), UQCRC1 (complex III), COX4 (complex IV), and ATP5A (complex V). (B) Oxygen consumption rate (OCR) of intact cells stably expressing EV and WT, S47A, S47E Cytc measured in Seahorse media supplemented with $10 \mathrm{mM}$ galactose using the Seahorse bioanalyzer $(n=9-13)$. (C) Extracellular acidification rate (ECAR) of intact cells as a measure of the rate of glycolysis measured in Seahorse media supplemented with $10 \mathrm{mM}$ glucose and $10 \mathrm{mM}$ sodium pyruvate $(n=4-6)$. Data are represented as means $\pm \mathrm{SEM},{ }^{*} p<0.05$.

\subsection{S47E Cytc Expressing Cells Have a Lower Mitochondrial Membrane Potential ( $\Psi \Psi m)$ That Corresponds to} Lower ROS Production

The mitochondrial membrane potential $\left(\Delta \Psi_{\mathrm{m}}\right)$ in our cell lines was assessed using the ratiometric JC-1 probe. The JC-1 probe diffuses into the mitochondria and accumulates and aggregates when $\Delta \Psi_{\mathrm{m}}$ is high, resulting in red fluorescence. At low $\Delta \Psi_{\mathrm{m}}$, it exists as a monomer that emits green fluorescence. Therefore, the ratio of red/green fluorescence provides a relative measure for $\Delta \Psi_{\mathrm{m}}$. FCCP, a potent uncoupler of $\Delta \Psi_{\mathrm{m}}$, was used as a control. The phosphomimetic S47E Cytc cell line resulted in a statistically significant $21 \%$ decrease in fluorescence compared to the WT Cytc expressing cell line, indicating that the phosphomimetic replacement led to a reduction in $\Delta \Psi_{\mathrm{m}}$ (Figure 2A). It has been shown that $\Delta \Psi_{\mathrm{m}}$ is proportional to mitochondrial ROS production. However, $\Delta \Psi_{\mathrm{m}}$ and ROS do not have a linear relationship [5]. Minimal ROS levels and optimal ATP levels are maintained within a physiological, intermediate membrane potential range of about 80-120 $\mathrm{mV}$ [23]. When $\Delta \Psi_{\mathrm{m}}$ exceeds $140 \mathrm{mV}$, this results in an exponential increase in ROS that can be detrimental and trigger cell death $[5,17]$. We analyzed mitochondrial ROS production in the four cell lines using the mitochondria-specific fluorescent superoxide indicator MitoSOX. Cells expressing phosphomimetic S47E Cytc showed a 30\% decreased MitoSOX fluorescence, demonstrating reduced mitochondrial 
superoxide production compared to the WT control cell line (Figure 2B). We also probed our cell lysates for 4-HNE (4-hydroxynonenal), a product of lipid peroxidation that is an indirect readout of total cellular ROS [24]. Our results confirmed significantly lower total 4-HNE levels for the S47E phosphomimetic cell line compared to WT and S47A Cytc expressing cell lines (Figure 2C,D). This finding is consistent with the direct relationship between $\Delta \Psi_{\mathrm{m}}$ and ROS production. Finally, bioluminescence produced by the ATP-dependent luciferase catalyzed luciferin oxidation reaction was used to measure cellular ATP levels. In agreement with the higher oxygen consumption rates and $\Delta \Psi_{\mathrm{m}}$ levels, both WT and S47A Cytc expressing cells showed a trend towards slightly increased ATP levels compared to the S47E Cytc expressing cell line (Figure 2E).

A

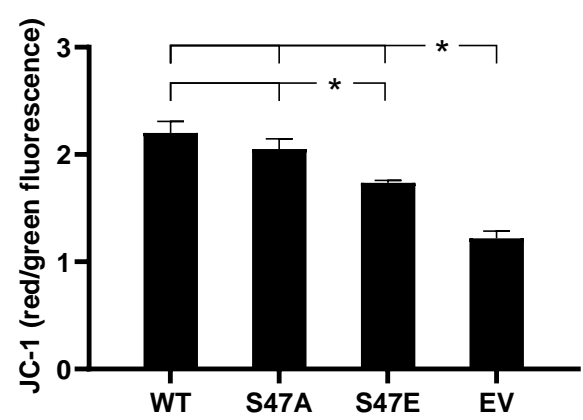

C

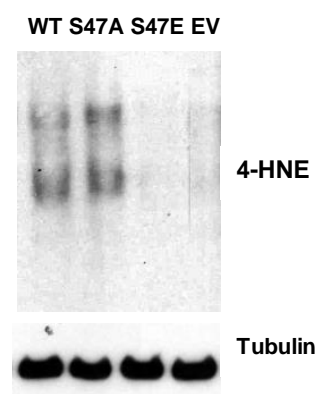

\section{E}

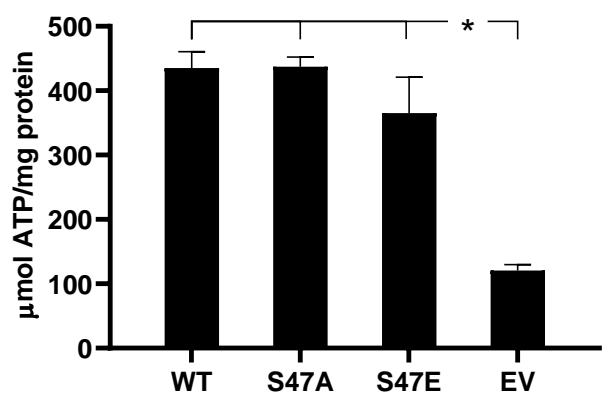

B

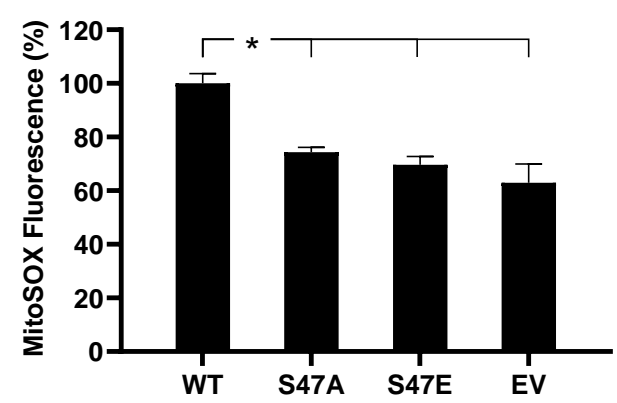

D

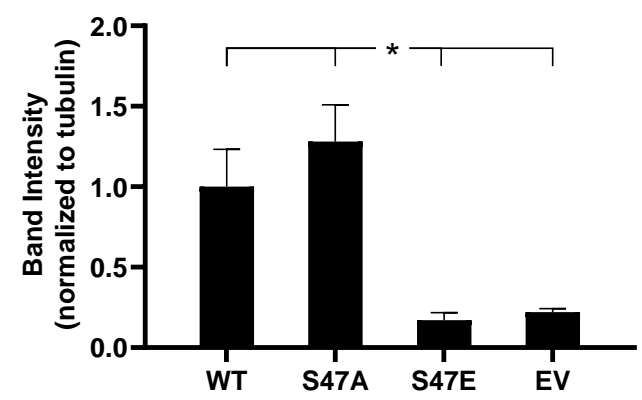

Figure 2. (A) Mitochondrial membrane potential $\left(\Delta \Psi_{\mathrm{m}}\right)$ of intact cells measured using red/green fluorescence distribution of the ratiometric JC-1 probe $(n=6)$. (B) Mitochondrial reactive oxygen species (ROS) production in intact cells measured as \% of MitoSOX fluorescence $(n=4)$. (C) 4-hydroxynonenal (4-HNE), a product of lipid peroxidation, immunoblotted on cells stably expressing EV and WT, S47A, S47E Cytc. (D) Quantification of 4-HNE band density using ImageJ software $(n=3)$. (E) ATP levels in the cell lines stably expressing EV and WT, S47A, S47E Cytc $(n=3)$. Data are represented as means $\pm \mathrm{SEM}, * p<0.05$. 


\subsection{Phosphomimetic S47E Cytc Attenuates ROS Production upon Oxygen-Glucose Deprivation/Reoxygenation (OGD/R)}

ROS generation under normal conditions is relatively low, however, ROS levels can profoundly increase during conditions of cell stress, such as reperfusion following ischemia [25]. Given the previously reported loss of $\mathrm{S} 47$ phosphorylation of Cytc under ischemia, we assessed the role of this modification using an oxygen-glucose deprivation/reoxygenation (OGD/R) model. This system was used to model ischemia/reperfusion injury in cultured cells [26]. We exposed our stably transfected cell lines to $1 \%$ oxygen (simulated hypoxia/ischemia) in glucose-depleted media for $90 \mathrm{~min}$, followed by reperfusion with MitoSOX supplemented complete culture media for $30 \mathrm{~min}$. MitoSOX fluorescence of the WT unphosphorylated Cytc expressing cells doubled upon reperfusion. In striking contrast, MitoSOX fluorescence in the S47E cell line and S47A cell line showed a non-significant increase of $8.8 \%$ and $9.2 \%$, respectively (Figure $3 \mathrm{~A}$ ). The S47E cell line displayed significantly reduced ROS levels under control conditions. However, upon exposure to simulated ischemia/reperfusion, this effect was even more prominent with a doubling of MitoSOX fluorescence in the WT cell line. This result depicts a protective role for the S47E phosphomimetic replacement in the context of ischemia/reperfusion injury. Similarly, we measured $\Delta \Psi_{\mathrm{m}}$ upon simulated reperfusion using the same OGD/R model. Here, we captured $\Delta \Psi_{\mathrm{m}}$ upon reperfusion. Similar to baseline conditions, the WT cell line showed a significantly higher $\Delta \Psi_{\mathrm{m}}$ compared to the S47E cell line upon reperfusion, indicating that phosphomimetic substitution maintained lower $\Delta \Psi_{\mathrm{m}}$ levels (Figure 3B). Our data thus drew a direct relationship between the speed of the electron transfer between Cytc and COX, intact cell respiration, $\Delta \Psi_{\mathrm{m}}$, and ROS.
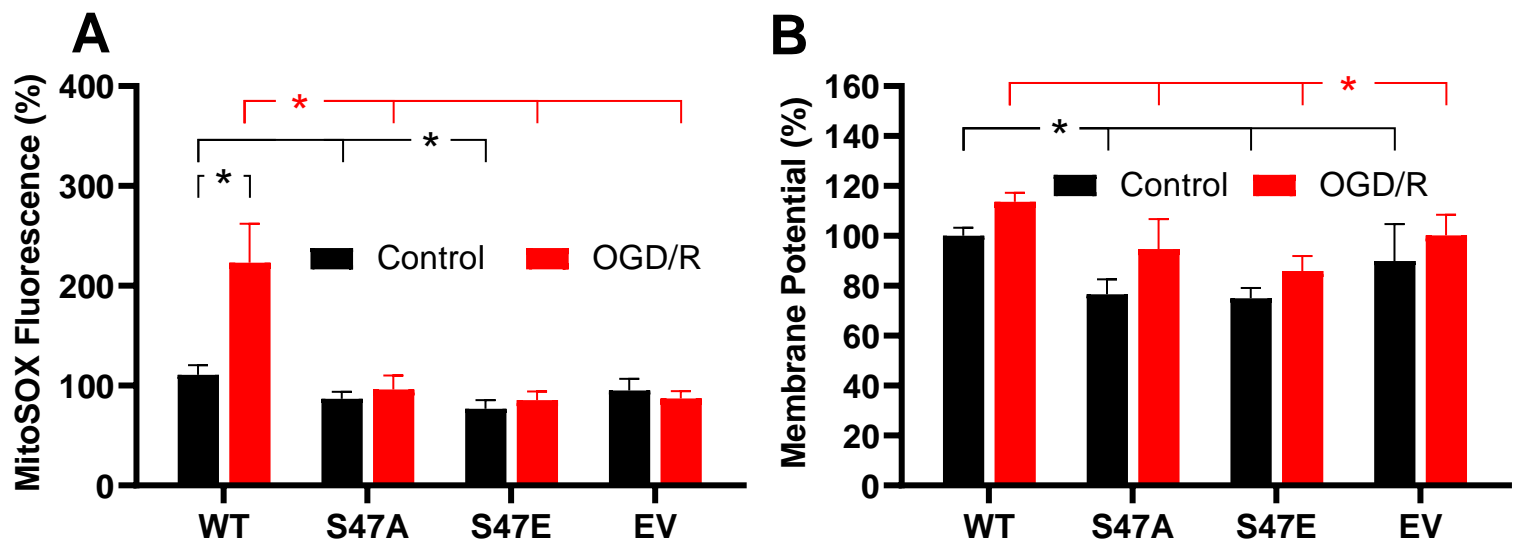

Figure 3. (A) ROS production following exposure to 90 min of oxygen-glucose deprivation, followed by 30 min of reoxygenation (OGD/R) $(n=9-10)$. (B) Mitochondrial membrane potential $\left(\Delta \Psi_{\mathrm{m}}\right)$ determined by JC-1 fluorescence after exposure to $90 \mathrm{~min}$ of oxygen-glucose deprivation, followed by $30 \mathrm{~min}$ of reoxygenation (OGD/R) ( $n=5-10)$. Black lines represent significant differences among control bars, while the red lines represent significant differences among OGD/R bars. Data are represented by means $\pm \mathrm{SEM}, * p<0.05$.

\subsection{Phosphomimetic S47E Cytc Protects against Cell Death upon OGD/R and $\mathrm{H}_{2} \mathrm{O}_{2}$ Treatment}

We assessed the impact of OGD/R on cell death using annexin V/propidium iodide (PI) staining, followed by flow cytometry analysis. Phosphatidylserine (PS) is a membrane lipid that is normally present in the inner leaflet of the plasma membrane. However, during apoptosis, PS flips to the outer leaflet of the plasma membrane. Annexin V, a calcium-dependent protein that binds to PS when fluorescently labeled, can be used to detect PS that is exposed on the outside of apoptotic cells. Apoptotic cells can be distinguished from necrotic cells by co-staining with PI [27]. PI is not cell-permeable and stains for nuclear DNA. Therefore, PI only stains necrotic cells, in which the cell membrane is damaged [28]. As a result, annexin V-positive cells represent early apoptotic cells, PI-positive cells 
represent necrotic cells, and annexin V- and PI-positive cells represent late apoptotic cells. Annexin V/PI staining of our cell lines following $12 \mathrm{~h}$ of OGD and $1 \mathrm{~h}$ of reperfusion showed that cells expressing S47E phosphomimetic Cytc resulted in significantly lower cell death (18\%) compared to the WT and S47A cell lines that resulted in $32.3 \%$ and $30 \%$ cell death, respectively (Figure $4 \mathrm{~A}, \mathrm{~B}$ ). We further assessed cell death in these cell lines upon $\mathrm{H}_{2} \mathrm{O}_{2}$ treatment, which causes cell death by inducing oxidative stress [29]. Annexin V/PI staining after treatment with $400 \mu \mathrm{M} \mathrm{H}_{2} \mathrm{O}_{2}$ for $16 \mathrm{~h}$ showed high levels of cell death in the WT control cells (25.2\%), whereas cells expressing S47E Cytc and S47A Cytc were better protected with only $11.2 \%$ and $13 \%$ cell death, respectively (Figure $5 \mathrm{~A}, \mathrm{~B}$ ). The protection of the S47A cell line against cell death upon $\mathrm{H}_{2} \mathrm{O}_{2}$ treatment, in comparison to OGD/R exposure, might be attributed to higher capacity of $\mathrm{H}_{2} \mathrm{O}_{2}$ scavenging ability shown by S47A recombinant Cytc (Figure S3B).

\section{A}

WT

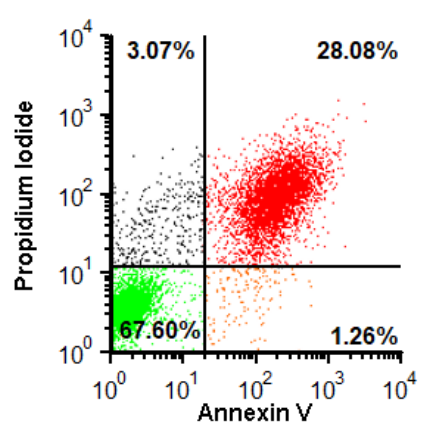

S47A

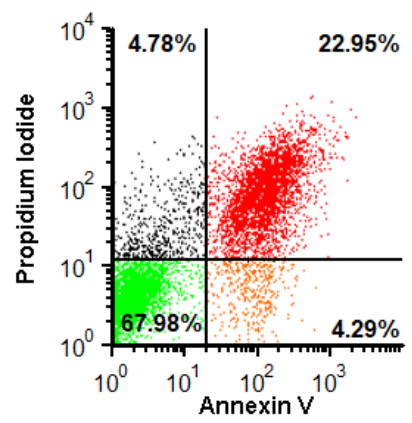

S47E

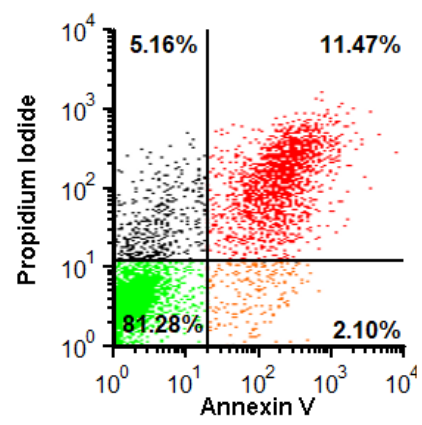

B
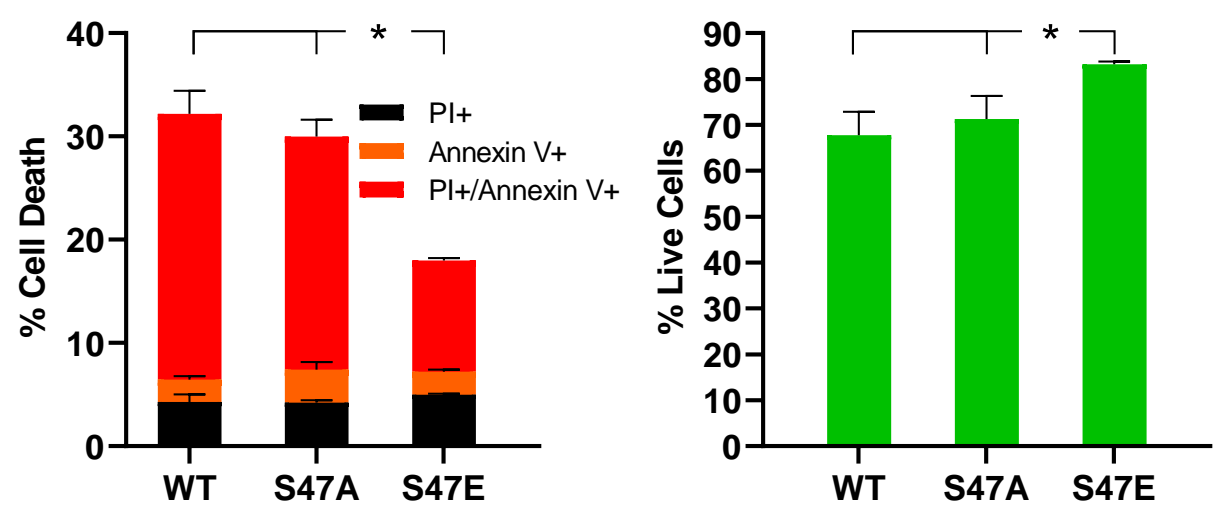

Figure 4. (A) Flow cytometry scatter plots representing necrotic (black, positive only for propidium iodide), early apoptotic (orange, positive only for annexin $\mathrm{V}$ ), late apoptotic (red, double-positive for propidium iodide and annexin V), and live cells (green, unstained) in WT, S47A, S47E Cytc expressing cells following exposure to oxygen-glucose deprivation for $12 \mathrm{~h}$, followed by reoxygenation for $1 \mathrm{~h}$. (B) Cell death represented as fractions of necrotic (black), early apoptotic (orange), and late apoptotic (red) cells. Live cells, represented in the lower left quadrant in the flow cytometry scatter plots, are shown as percent of total cells. The empty vector cell line was excluded due to near-complete cell death in the absence of glucose $(n=3-4)$. Data are represented as means \pm SEM, ${ }^{*} p<0.05$. 


\section{A}
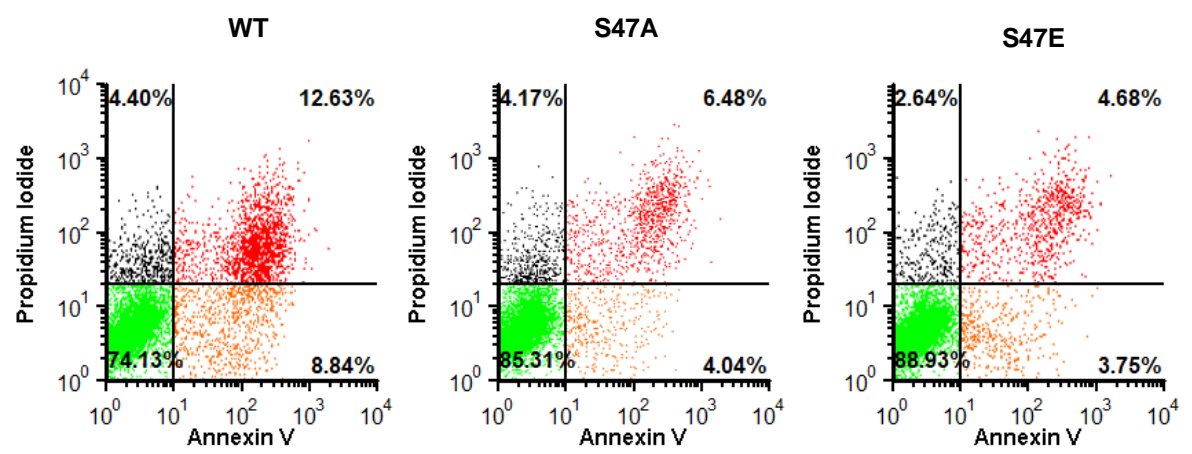

B
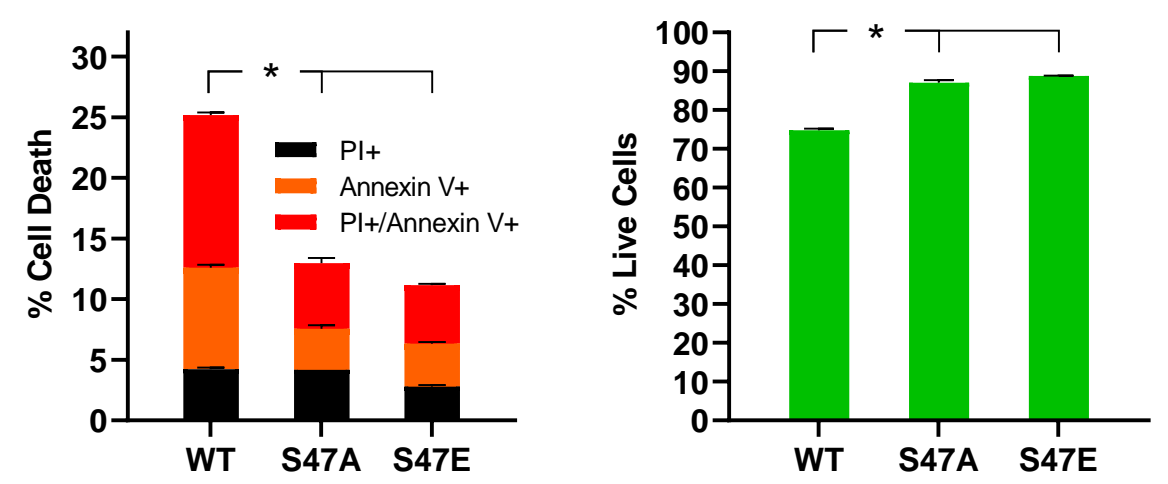

Figure 5. (A) Flow cytometry scatter plots representing necrotic (black, positive only for propidium iodide), early apoptotic (orange, positive only for annexin $\mathrm{V}$ ), late apoptotic (red, double-positive for propidium iodide and annexin V), and live cells (green, unstained) in WT, S47A, S47E Cytc expressing cells after treatment with $400 \mu \mathrm{M} \mathrm{H}_{2} \mathrm{O}_{2}$ for $16 \mathrm{~h}$. (B) Cell death represented as fractions of necrotic (black), early apoptotic (orange), and late apoptotic (red) cells. Live cells, represented in the lower left quadrant in the flow cytometry scatter plots, are shown as percent of total cells $(n=3)$. Data are represented by means $\pm \mathrm{SEM}, * p<0.05$.

\subsection{Akt Is a Potential Kinase Mediating S47 Phosphorylation of Cytc}

Our next goal was to determine the potential kinase that targets this highly regulatory S47 residue of Cytc for phosphorylation. We performed an in silico analysis using NetPhos 3.1 software [30] and found that Akt kinase could potentially target Cytc. We assessed the likelihood of S47 phosphorylation by performing an in vitro kinase assay with all three isoforms of Akt (Akt 1, Akt 2, and Akt 3). S47 is the only serine residue present in rodent Cytc. After probing the Akt kinase reactions with a phosphoserine antibody, we observed that all three isoforms of Akt could phosphorylate Cytc in a time-dependent manner in vitro (Figure 6A). In order to determine if the S47 phosphorylation of Cytc is mediated by Akt in tissues, we treated pig brain homogenates with a pharmacological activator of Akt, SC79, and an inhibitor of Akt, wortmannin. Akt activator SC79 binds to the pleckstrin homology $(\mathrm{PH})$ domain of Akt and changes the conformation that makes it favorable for phosphorylation by upstream kinases [31]. Wortmannin acts through non-competitive, irreversible inhibition of PI3K at a concentration of 2-4 $\mathrm{nM}$ [32]. Wortmannin has been found to inhibit Akt phosphorylation in a time and dose-dependent manner [33]. It inhibits myosin light chain kinase (MLCK) at a much higher concentration of $0.2 \mu \mathrm{M}$ and is not considered to be an inhibitor of phosphatidylinositol-4-kinase, protein kinase C, or c-Src tyrosine kinase [32]. Post-treatment, Cytc was purified from these tissue 
samples and assessed for its serine phosphorylation state. In the control sample, there was a basal level of serine phosphorylation. Upon treatment with the Akt inhibitor wortmannin, complete dephosphorylation of Cytc was observed, suggesting that this phosphorylation might be mediated by Akt. Upon treatment with the Akt activator SC79, serine phosphorylation of Cytc was observed (Figure 6B). Akt is known to translocate to the mitochondria when this signaling pathway is active, including the mitochondrial intermembrane space (IMS) where Cytc is located. This has been shown in several cell systems, including brain cells [34-36]. It has been further shown that of the three Akt isoforms, Akt2 localizes to the mitochondria [37,38]. We confirmed Akt translocation to the mitochondrial IMS in our pig brain mitochondrial fractions. Our mitochondrial fractionation results showed that S473-phosphorylated Akt and pan-Akt translocated to the mitochondrial IMS. Tubulin was used as a cytosolic marker, while COX4 and HSP60 were used as inner mitochondrial membrane and mitochondrial matrix markers, respectively (Figure 6C).

A

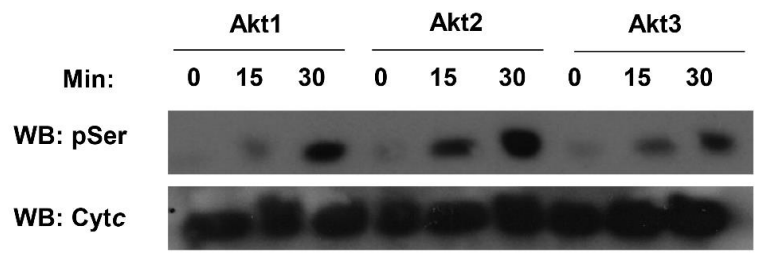

B

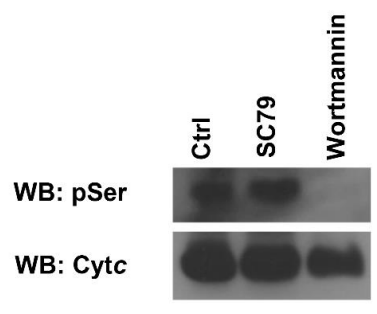

C

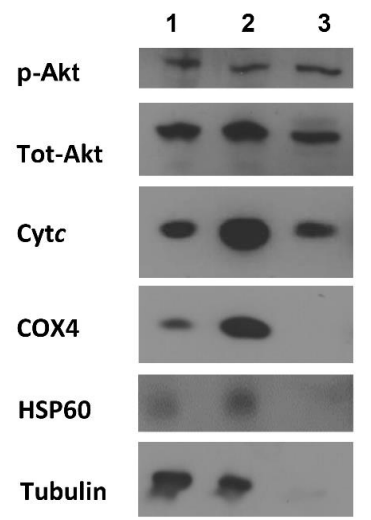

Figure 6. (A) In vitro Akt kinase assay showing a time-dependent increase in serine phosphorylation at 0,15 , and $30 \mathrm{~min}$. BSA was used as a negative control (not shown). (B) The purified pig brain Cytc, following SC79 (Akt activator), wortmannin (Akt inhibitor), and control (DMSO) treatments, was assessed for S47 phosphorylation. (C) Pig brain mitochondria fractionation. Lane1, pig brain tissue lysate; lane 2, crude mitochondria; lane 3, mitochondrial intermembrane space (IMS) fraction. COX4, HSP60, and tubulin were used as an inner mitochondrial membrane (IMM), mitochondrial matrix, and cytosolic markers, respectively. 


\section{Discussion}

Our lab previously showed that 547 phosphorylation of Cytc is an important modification that regulates COX and caspase-3 activity in the mammalian brain [12]. In this paper we expanded on our studies by characterizing phosphomimetic S47E Cytc in a cell culture system. We previously established that S47E is an excellent mimic to study S47 phosphorylation of Cytc based on the spatial arrangement of S47E in the crystal structure (6N1O.pdb) and functional studies using in vivo S47 phosphorylated and S47E Cytc side by side [12]. We overexpressed WT, S47A, and S47E Cytc in Cytc double-knockout lung fibroblasts [21]. It is important that both the somatic and testes isoforms of Cytc are knocked out from these cells because, in the absence of the somatic isoform, the testes isoform may be induced [21]. Both somatic and testes Cytc encode Cytc isoforms consisting of 104 amino acids, with $86 \%$ identical residues between the two [39]. There are multiple pseudogenes of somatic Cytc in human and mouse genomes [40]. However, humans express only one active isoform of Cytc that shows features of both the rodent somatic and testes isoforms. Once Cytc is stably reintroduced into the Cytc double-knockout cells, they start expressing higher levels of complexes I, III, and IV, which are known to form supercomplexes and are downregulated in the absence of Cytc [41,42]. This supports the findings from a previous study that suggested a role of Cytc in the assembly and stability of respiratory supercomplexes [43].

The effect on intact cell respiration observed in the presence of S47E Cytc was similar to the decrease in COX activity reported in vitro with a Clark-type oxygen electrode [12] (Table 1). The observation that the rate of the ETC flux could be modulated by modifications of Cytc further supported our model that the reaction between Cytc and COX can serve as the rate-limiting step of the ETC controlling overall ETC flux [2]. In addition, there is evidence that the S47 residue of Cytc may also interact with the $b c_{1}$ complex [44]. Therefore, modifications at this residue may affect electron transfer from the $b c_{1}$ complex, lowering overall ETC activity. The phosphomimetic S47E cell line showed higher glycolytic flux compared to the unphosphorylated WT cell line, likely compensating for the lower mitochondrial oxygen consumption. The ATP level for S47E was lower than that of WT and S47A; however, the difference was not statistically significant. It should also be noted that in vivo phosphorylation of the Cytc pool in the brain will never reach $100 \%$, whereas all Cytc in the cells expressing S47E Cytc possess the phosphomimetic modification. Therefore, the effect of Cytc phosphorylation on ATP levels may be negligible in the mammalian brain.

The partial inhibition of respiration observed in the S47E Cytc expressing cell line is important because, under physiological conditions, respiration and mitochondrial $\Delta \Psi_{\mathrm{m}}$ are directly related. In addition, it has been estimated that $95 \%$ of ROS are generated from electron leak in the respiratory complexes of the ETC in normal cells [25]. Maintenance of intermediate $\Delta \Psi_{\mathrm{m}}(100-120 \mathrm{mV})$ avoids excessive ROS generation but provides the full capability to produce ATP because maximal rates of ATP synthesis by ATP synthase take place at an intermediate $\Delta \Psi_{\mathrm{m}}$ of $100-120 \mathrm{mV}$ [45]. At $\Delta \Psi_{\mathrm{m}}>140 \mathrm{mV}$, ROS production at ETC complexes I and III increases exponentially, whereas mitochondria of resting cells with an optimal, intermediate $\Delta \Psi_{\mathrm{m}}$ do not produce significant amounts of ROS [46,47]. This relationship between $\Delta \Psi_{\mathrm{m}}$ and ROS is evident from our results and further tested in the context of ischemia/reperfusion injury by using an OGD/R cell culture model. The unphosphorylated WT Cytc expressing cells showed a significant increase in ROS following OGD/R. The phosphomimetic cell line attenuated ROS production, further establishing a protective role for S47 phosphorylation in the context of ischemia/reperfusion injury. Our model proposes that cell signaling pathways target the ETC. However, under conditions of stress, such as ischemia/reperfusion, there is an influx of calcium into the mitochondria [48-50]. It has been demonstrated that calcium is a potent activator of the mitochondrial ETC [51]. This hyperactivity is likely mediated by dephosphorylation of mitochondrial proteins, including Cytc, mediated by calcium-dependent phosphatases [52]. The increase in ETC activity leads to pathologically high $\Delta \Psi_{\mathrm{m}}$ levels and a burst of ROS that triggers cell death as a result of ischemia/reperfusion injury (reviewed in [5]). As predicted from our model, the protective role of S47E Cytc was evident from significantly lower cell death reported upon exposure to OGD/R. 
In addition, the phosphomimetic cell line showed greater cell viability upon treatment with hydrogen peroxide. Other contributing factors explaining reduced cell death could be lowered caspase- 3 activity and cardiolipin peroxidase activity as was previously reported for $\mathrm{S} 47$ phosphomimetic Cytc [12,53]. S47A and S47E Cytc resulted in 38\% and 35\% caspase-3 activity, respectively, compared to WT. Both the mutants also resulted in significantly lower cardiolipin peroxidase activity compared to WT at varying ratios of cardiolipin to Cytc (Table 1). These functional parameters may explain the lower cell death observed when $\mathrm{S} 47$ residue of Cytc is modified.

Table 1. Summary of the effect of WT, S47A, and S47E Cytc on different mitochondrial functions involving Cytc.

\begin{tabular}{|c|c|c|c|c|c|}
\hline Cytc Function & WT & S47A & S47E/S47D & EV & Reference \\
\hline $\begin{array}{c}\text { Brain cytochrome } c \text { oxidase (COX) } \\
\text { activity }\end{array}$ & $100 \%$ & $\sim 82 \%$ & $\sim 46 \%$ & - & [12] \\
\hline \multirow{2}{*}{ Caspase- 3 activity } & $100 \%$ & $\sim 38 \%$ & $\sim 35 \%$ & - & [12] \\
\hline & $100 \%$ & $\sim 50 \%$ & $\sim 30 \%$ & & {$[53]$} \\
\hline \multirow{2}{*}{$\begin{array}{l}\text { Cardiolipin peroxidase activity } \\
\text { (cardiolipin: } \mathrm{Cyt} \text { ) }\end{array}$} & $\begin{array}{l}100 \%(10: 1) \\
100 \%(20: 1)\end{array}$ & $\begin{array}{l}\sim 37 \%(10: 1) \\
\sim 54 \%(20: 1)\end{array}$ & $\begin{array}{l}\sim 50 \%(10: 1) \\
\sim 51 \%(20: 1)\end{array}$ & - & [12] \\
\hline & $100 \%(100: 1)$ & $\sim 60 \%(100: 1)$ & $\sim 80 \%(100: 1)$ & & [53] \\
\hline Intact cell respiration & $100 \%$ & $\sim 81 \%$ & $\sim 42 \%$ & $\sim 15 \%$ & This study \\
\hline Mitochondrial membrane potential & $100 \%$ & $\sim 93 \%$ & $\sim 79 \%$ & $\sim 55 \%$ & This study \\
\hline Mitochondrial ROS production & $100 \%$ & $\sim 74 \%$ & $\sim 70 \%$ & $\sim 63 \%$ & This study \\
\hline ATP production & $100 \%$ & $\sim 100 \%$ & $\sim 84 \%$ & $\sim 28 \%$ & This study \\
\hline Cell death (after OGD/R) & $\sim 32 \%$ & $\sim 30 \%$ & $\sim 18 \%$ & - & This study \\
\hline Cell death (after $\mathrm{H}_{2} \mathrm{O}_{2}$ treatment) & $\sim 25 \%$ & $\sim 13 \%$ & $\sim 11 \%$ & - & This study \\
\hline
\end{tabular}

Finally, we presented data suggesting that pro-survival kinase Akt could target S47 for phosphorylation. S47 is the only serine residue present in rodent Cytc, making it a unique regulatory site in mammals. In vitro kinase assays with all three Akt isoforms resulted in a time-dependent increase in serine phosphorylation. We also used pharmacological Akt activator SC79 and inhibitor wortmannin in pig brain tissue lysates to modulate the signaling pathway. The analysis of Cytc phosphorylation state post-treatment resulted in complete dephosphorylation of Cytc in the presence of wortmannin, suggesting a potential role for Akt in mediating this pathway. Interestingly, several studies have shown that Akt activator SC79 is an effective treatment for cerebral ischemia/reperfusion injury in animal models [54-56]. We and others have shown that activated, phosphorylated Akt translocates to the mitochondrial IMS where Cytc resides [34-36]. This suggests that Cytc is targeted for $\mathrm{S} 47$ phosphorylation by Akt, which, in turn, results in optimal, intermediate $\Delta \Psi_{\mathrm{m}}$ levels, lower ROS production, and significant protection from cell death upon OGD/R and other stresses. This experimental model is further supported by our recently discovered specific wavelengths of infrared light that partially inhibits the reaction between Cytc and COX, mimicking a protective effect similar to that observed with 547 phosphorylation of Cytc [57,58]. In conclusion, our study establishes the cytoprotective role of $S 47$ phosphorylation in cerebral ischemia/reperfusion injury.

Supplementary Materials: The following are available online at http://www.mdpi.com/2073-4409/9/8/1843/s1, Figure S1: Mitochondrial stress test in Seahorse media supplemented with $10 \mathrm{mM}$ galactose, Figure S2: Mitochondrial stress test in Seahorse media supplemented with $10 \mathrm{mM}$ glucose and $10 \mathrm{mM}$ sodium pyruvate, Figure S3: Glycolysis stress test based on extracellular acidification rate (ECAR) of cells in Seahorse media supplemented with $10 \mathrm{mM}$ glucose and $10 \mathrm{mM}$ sodium pyruvate, and rate of Cytc oxidation upon addition of $\mathrm{H}_{2} \mathrm{O}_{2}$. 
Author Contributions: H.A.K., J.W., P.T.M., I.L. and M.H. designed and performed experiments. H.A.K. and M.H. wrote the manuscript. All authors edited and approved the final version of the manuscript. The authors declare that they have no conflicts of interest with the contents of this article. All authors have read and agreed to the published version of the manuscript.

Funding: This work was supported by the U.S. National Institutes of Health grant R01 GM116807, American Heart Association grant \#20PRE35210130/Hasini Kalpage/2020, Wayne State University's Graduate Research Assistant Fellowship, and by the Office of the Assistant Secretary of Defense for Health Affairs through the Peer-Reviewed Medical Research Program under Award W81XWH-16-1-0175.

Acknowledgments: Opinions, interpretations, conclusions, and recommendations are those of the authors and are not necessarily endorsed by the National Institutes of Health, American Heart Association, or the U.S. Department of Defense. We thank Moh H. Malek and Gerry Hish at Wayne State University for providing pig brain tissue, Christian Reynolds at Wayne State University for access to a hypoxia chamber for OGD/R experiments, and Carlos Moraes at the University of Miami for providing the Cytc knockout cell line.

Conflicts of Interest: The authors declare no conflict of interest.

$\begin{array}{ll}\text { Abbreviations } \\ \text { COX } & \text { cytochrome } c \text { oxidase } \\ \text { Cytc } & \text { cytochrome } c \\ \Delta \Psi_{\mathrm{m}} & \text { mitochondrial membrane potential } \\ \text { ETC } & \text { electron transport chain } \\ \text { OGD/R } & \text { oxygen-glucose deprivation/reoxygenation } \\ \text { OxPhos } & \text { oxidative phosphorylation } \\ \text { ROS } & \text { reactive oxygen species }\end{array}$

\section{References}

1. Hüttemann, M.; Pecina, P.; Rainbolt, M.; Sanderson, T.H.; Kagan, V.E.; Samavati, L.; Doan, J.W.; Lee, I. The multiple functions of cytochrome $\mathrm{c}$ and their regulation in life and death decisions of the mammalian cell: From respiration to apoptosis. Mitochondrion 2011, 11, 369-381. [CrossRef] [PubMed]

2. Kalpage, H.A.; Wan, J.; Morse, P.T.; Zurek, M.P.; Turner, A.A.; Khobeir, A.; Yazdi, N.; Hakim, L.; Liu, J.; Vaishnav, A.; et al. Cytochrome c phosphorylation: Control of mitochondrial electron transport chain flux and apoptosis. Int. J. Biochem. Cell Biol. 2020, 121, 105704. [CrossRef] [PubMed]

3. Galluzzi, L.; Vitale, I.; Abrams, J.M.; Alnemri, E.S.; Baehrecke, E.H.; Blagosklonny, M.V.; Dawson, T.M.; Dawson, V.L.; El-Deiry, W.S.; Fulda, S.; et al. Molecular definitions of cell death subroutines: Recommendations of the Nomenclature Committee on Cell Death 2012. Cell Death Differ. 2012, 19, 107-120. [CrossRef] [PubMed]

4. Tang, D.; Kang, R.; Berghe, T.V.; Vandenabeele, P.; Kroemer, G. The molecular machinery of regulated cell death. Cell Res. 2019, 29, 347-364. [CrossRef] [PubMed]

5. Kalpage, H.A.; Bazylianska, V.; Recanati, M.A.; Fite, A.; Liu, J.; Wan, J.; Mantena, N.; Malek, M.H.; Podgorski, I.; Heath, E.I.; et al. Tissue-specific regulation of cytochrome c by post-translational modifications: Respiration, the mitochondrial membrane potential, ROS, and apoptosis. FASEB J. 2019, 33, 1540-1553. [CrossRef] [PubMed]

6. Dalmonte, M.E.; Forte, E.; Genova, M.L.; Giuffre, A.; Sarti, P.; Lenaz, G. Control of respiration by cytochrome c oxidase in intact cells: Role of the membrane potential. J. Biol. Chem. 2009, 284, 32331-32335. [CrossRef]

7. Kunz, W.S.; Kudin, A.; Vielhaber, S.; Elger, C.E.; Attardi, G.; Villani, G. Flux control of cytochrome c oxidase in human skeletal muscle. J. Biol. Chem. 2000, 275, 27741-27745. [CrossRef]

8. Lee, I.; Salomon, A.R.; Yu, K.; Doan, J.W.; Grossman, L.I.; Hüttemann, M. New prospects for an old enzyme: Mammalian cytochrome $c$ is tyrosine-phosphorylated in vivo. Biochemistry 2006, 45, 9121-9128. [CrossRef]

9. Sanderson, T.H.; Mahapatra, G.; Pecina, P.; Ji, Q.; Yu, K.; Sinkler, C.; Varughese, A.; Kumar, R.; Bukowski, M.J.; Tousignant, R.N.; et al. Cytochrome $\mathrm{c}$ is tyrosine 97 phosphorylated by neuroprotective insulin treatment. PLoS ONE 2013, 8, e78627. [CrossRef]

10. Yu, H.; Lee, I.; Salomon, A.R.; Yu, K.; Hüttemann, M. Mammalian liver cytochrome $c$ is tyrosine-48 phosphorylated in vivo, inhibiting mitochondrial respiration. Biochim. Et Biophys. Acta 2008, 1777, 1066-1071. [CrossRef] 
11. Mahapatra, G.; Varughese, A.; Ji, Q.; Lee, I.; Liu, J.; Vaishnav, A.; Sinkler, C.; Kapralov, A.A.; Moraes, C.T.; Sanderson, T.H.; et al. Phosphorylation of Cytochrome c Threonine 28 Regulates Electron Transport Chain Activity in Kidney: IMPLICATIONS FOR AMP KINASE. J. Biol. Chem. 2017, 292, 64-79. [CrossRef]

12. Kalpage, H.A.; Vaishnav, A.; Liu, J.; Varughese, A.; Wan, J.; Turner, A.A.; Ji, Q.; Zurek, M.P.; Kapralov, A.A.; Kagan, V.E.; et al. Serine-47 phosphorylation of cytochrome $\mathrm{c}$ in the mammalian brain regulates cytochrome c oxidase and caspase-3 activity. FASEB J. 2019, 33, 13503-13514. [CrossRef] [PubMed]

13. Wan, J.; Kalpage, H.A.; Vaishnav, A.; Liu, J.; Lee, I.; Mahapatra, G.; Turner, A.A.; Zurek, M.P.; Ji, Q.; Moraes, C.T.; et al. Regulation of Respiration and Apoptosis by Cytochrome c Threonine 58 Phosphorylation. Sci. Rep. 2019, 9, 15815. [CrossRef] [PubMed]

14. Pecina, P.; Borisenko, G.G.; Belikova, N.A.; Tyurina, Y.Y.; Pecinova, A.; Lee, I.; Samhan-Arias, A.K.; Przyklenk, K.; Kagan, V.E.; Hüttemann, M. Phosphomimetic substitution of cytochrome c tyrosine 48 decreases respiration and binding to cardiolipin and abolishes ability to trigger downstream caspase activation. Biochemistry 2010, 49, 6705-6714. [CrossRef] [PubMed]

15. Hou, Y.; Wang, J.; Feng, J. The neuroprotective effects of curcumin are associated with the regulation of the reciprocal function between autophagy and HIF-1alpha in cerebral ischemia-reperfusion injury. Drug Des. Dev. Ther. 2019, 13, 1135-1144. [CrossRef] [PubMed]

16. Rodrigo, R.; Fernandez-Gajardo, R.; Gutierrez, R.; Matamala, J.M.; Carrasco, R.; Miranda-Merchak, A.; Feuerhake, W. Oxidative stress and pathophysiology of ischemic stroke: Novel therapeutic opportunities. CNS Neurol. Disord. Drug Targets 2013, 12, 698-714. [CrossRef] [PubMed]

17. Sanderson, T.H.; Reynolds, C.A.; Kumar, R.; Przyklenk, K.; Hüttemann, M. Molecular mechanisms of ischemia-reperfusion injury in brain: Pivotal role of the mitochondrial membrane potential in reactive oxygen species generation. Mol. Neurobiol. 2013, 47, 9-23. [CrossRef]

18. Granger, D.N.; Kvietys, P.R. Reperfusion injury and reactive oxygen species: The evolution of a concept. Redox Biol. 2015, 6, 524-551. [CrossRef]

19. Angelova, P.R.; Abramov, A.Y. Role of mitochondrial ROS in the brain: From physiology to neurodegeneration. FEBS Lett. 2018, 592, 692-702. [CrossRef]

20. Sun, Y.; Zhu, W.; Zhou, S.; Wang, Z.; Chen, X.; Jia, L. Exploring the model of PC12 apoptosis induced by OGSD/R through in vitro experiments. Oncotarget 2017, 8, 90176-90184. [CrossRef]

21. Vempati, U.D.; Diaz, F.; Barrientos, A.; Narisawa, S.; Mian, A.M.; Millan, J.L.; Boise, L.H.; Moraes, C.T. Role of cytochrome $\mathrm{C}$ in apoptosis: Increased sensitivity to tumor necrosis factor alpha is associated with respiratory defects but not with lack of cytochrome C release. Mol. Cell. Biol. 2007, 27, 1771-1783. [CrossRef] [PubMed]

22. TeSlaa, T.; Teitell, M.A. Techniques to monitor glycolysis. Methods Enzymol. 2014, 542, 91-114. [CrossRef] [PubMed]

23. Hüttemann, M.; Lee, I.; Pecinova, A.; Pecina, P.; Przyklenk, K.; Doan, J.W. Regulation of oxidative phosphorylation, the mitochondrial membrane potential, and their role in human disease. J. Bioenerg. Biomembr. 2008, 40, 445-456. [CrossRef]

24. Breitzig, M.; Bhimineni, C.; Lockey, R.; Kolliputi, N. 4-Hydroxy-2-nonenal: A critical target in oxidative stress? Am. J. Physiol. Cell Physiol. 2016, 311, C537-C543. [CrossRef]

25. Kalogeris, T.; Bao, Y.; Korthuis, R.J. Mitochondrial reactive oxygen species: A double edged sword in ischemia/reperfusion vs preconditioning. Redox Biol. 2014, 2, 702-714. [CrossRef] [PubMed]

26. Ryou, M.G.; Mallet, R.T. An In Vitro Oxygen-Glucose Deprivation Model for Studying Ischemia-Reperfusion Injury of Neuronal Cells. Methods Mol. Biol. (Clifton N. J.) 2018, 1717, 229-235. [CrossRef]

27. Crowley, L.C.; Marfell, B.J.; Scott, A.P.; Waterhouse, N.J. Quantitation of Apoptosis and Necrosis by Annexin V Binding, Propidium Iodide Uptake, and Flow Cytometry. Cold Spring Harb. Protoc. 2016. [CrossRef]

28. Lecoeur, H. Nuclear apoptosis detection by flow cytometry: Influence of endogenous endonucleases. Exp. Cell Res. 2002, 277, 1-14. [CrossRef]

29. Park, W.H. $\mathrm{H}(2) \mathrm{O}(2)$ inhibits the growth of human pulmonary fibroblast cells by inducing cell death, GSH depletion and G1 phase arrest. Mol. Med. Rep. 2013, 7, 1235-1240. [CrossRef]

30. Blom, N.; Sicheritz-Ponten, T.; Gupta, R.; Gammeltoft, S.; Brunak, S. Prediction of post-translational glycosylation and phosphorylation of proteins from the amino acid sequence. Proteomics 2004, 4, 1633-1649. [CrossRef] 
31. Jo, H.; Mondal, S.; Tan, D.; Nagata, E.; Takizawa, S.; Sharma, A.K.; Hou, Q.; Shanmugasundaram, K.; Prasad, A.; Tung, J.K.; et al. Small molecule-induced cytosolic activation of protein kinase Akt rescues ischemia-elicited neuronal death. Proc. Natl. Acad. Sci. USA 2012, 109, 10581-10586. [CrossRef] [PubMed]

32. Powis, G.; Bonjouklian, R.; Berggren, M.M.; Gallegos, A.; Abraham, R.; Ashendel, C.; Zalkow, L.; Matter, W.F.; Dodge, J.; Grindey, G.; et al. Wortmannin, a potent and selective inhibitor of phosphatidylinositol-3-kinase. Cancer Res. 1994, 54, 2419-2423. [PubMed]

33. Ng, S.S.; Tsao, M.S.; Nicklee, T.; Hedley, D.W. Wortmannin inhibits pkb/akt phosphorylation and promotes gemcitabine antitumor activity in orthotopic human pancreatic cancer xenografts in immunodeficient mice. Clin. Cancer Res. 2001, 7, 3269-3275. [PubMed]

34. Bijur, G.N.; Jope, R.S. Rapid accumulation of Akt in mitochondria following phosphatidylinositol 3-kinase activation. J. Neurochem. 2003, 87, 1427-1435. [CrossRef] [PubMed]

35. Marchi, S.; Corricelli, M.; Branchini, A.; Vitto, V.A.M.; Missiroli, S.; Morciano, G.; Perrone, M.; Ferrarese, M.; Giorgi, C.; Pinotti, M.; et al. Akt-mediated phosphorylation of MICU1 regulates mitochondrial $\mathrm{Ca}(2+)$ levels and tumor growth. EMBO J. 2019, 38. [CrossRef]

36. Chae, Y.C.; Vaira, V.; Caino, M.C.; Tang, H.Y.; Seo, J.H.; Kossenkov, A.V.; Ottobrini, L.; Martelli, C.; Lucignani, G.; Bertolini, I.; et al. Mitochondrial Akt Regulation of Hypoxic Tumor Reprogramming. Cancer Cell 2016, 30, 257-272. [CrossRef]

37. Santi, S.A.; Lee, H. The Akt isoforms are present at distinct subcellular locations. Am. J. Physiol. 2010, 298, C580-C591. [CrossRef]

38. Ghosh, J.C.; Siegelin, M.D.; Vaira, V.; Faversani, A.; Tavecchio, M.; Chae, Y.C.; Lisanti, S.; Rampini, P.; Giroda, M.; Caino, M.C.; et al. Adaptive mitochondrial reprogramming and resistance to PI3K therapy. J. Natl. Cancer Inst. 2015, 107. [CrossRef]

39. Narisawa, S.; Hecht, N.B.; Goldberg, E.; Boatright, K.M.; Reed, J.C.; Millan, J.L. Testis-specific cytochrome c-null mice produce functional sperm but undergo early testicular atrophy. Mol. Cell. Biol. 2002, 22, 5554-5562. [CrossRef]

40. Limbach, K.J.; Wu, R. Characterization of a mouse somatic cytochrome c gene and three cytochrome c pseudogenes. Nucleic Acids Res. 1985, 13, 617-630. [CrossRef]

41. Sousa, J.S.; D’Imprima, E.; Vonck, J. Mitochondrial Respiratory Chain Complexes. Sub Cell. Biochem. 2018, 87, 167-227. [CrossRef]

42. Perez-Mejias, G.; Guerra-Castellano, A.; Diaz-Quintana, A.; De la Rosa, M.A.; Diaz-Moreno, I. Cytochrome c: Surfing Off of the Mitochondrial Membrane on the Tops of Complexes III and IV. Comput. Struct. Biotechnol. 2019, 17, 654-660. [CrossRef] [PubMed]

43. Vempati, U.D.; Han, X.; Moraes, C.T. Lack of cytochrome c in mouse fibroblasts disrupts assembly/stability of respiratory complexes I and IV. J. Biol. Chem. 2009, 284, 4383-4391. [CrossRef]

44. Kokhan, O.; Wraight, C.A.; Tajkhorshid, E. The binding interface of cytochrome c and cytochrome c(1) in the bc(1) complex: Rationalizing the role of key residues. Biophys J. 2010, 99, 2647-2656. [CrossRef] [PubMed]

45. Kaim, G.; Dimroth, P. ATP synthesis by F-type ATP synthase is obligatorily dependent on the transmembrane voltage. EMBO J. 1999, 18, 4118-4127. [CrossRef] [PubMed]

46. Liu, S.S. Cooperation of a "reactive oxygen cycle" with the $\mathrm{Q}$ cycle and the proton cycle in the respiratory chain-superoxide generating and cycling mechanisms in mitochondria. J. Bioenerg. Biomembr. 1999, 31, 367-376. [CrossRef]

47. Korshunov, S.S.; Skulachev, V.P.; Starkov, A.A. High protonic potential actuates a mechanism of production of reactive oxygen species in mitochondria. FEBS Lett. 1997, 416, 15-18. [CrossRef]

48. Miklos, Z.; Ivanics, T.; Roemen, T.H.; van der Vusse, G.J.; Dezsi, L.; Szekeres, M.; Kemecsei, P.; Toth, A.; Kollai, M.; Ligeti, L. Time related changes in calcium handling in the isolated ischemic and reperfused rat heart. Mol. Cell. Biochem. 2003, 250, 115-124. [CrossRef]

49. Bull, R.; Finkelstein, J.P.; Galvez, J.; Sanchez, G.; Donoso, P.; Behrens, M.I.; Hidalgo, C. Ischemia enhances activation by $\mathrm{Ca} 2+$ and redox modification of ryanodine receptor channels from rat brain cortex. J. Neurosci. 2008, 28, 9463-9472. [CrossRef]

50. Robb-Gaspers, L.D.; Burnett, P.; Rutter, G.A.; Denton, R.M.; Rizzuto, R.; Thomas, A.P. Integrating cytosolic calcium signals into mitochondrial metabolic responses. EMBO J. 1998, 17, 4987-5000. [CrossRef]

51. McCormack, J.G.; Denton, R.M. The role of intramitochondrial Ca2+ in the regulation of oxidative phosphorylation in mammalian tissues. Biochem. Soc. Trans. 1993, 21, 793-799. [CrossRef] [PubMed] 
52. Hopper, R.K.; Carroll, S.; Aponte, A.M.; Johnson, D.T.; French, S.; Shen, R.F.; Witzmann, F.A.; Harris, R.A.; Balaban, R.S. Mitochondrial matrix phosphoproteome: Effect of extra mitochondrial calcium. Biochemistry 2006, 45, 2524-2536. [CrossRef]

53. Guerra-Castellano, A.; Diaz-Moreno, I.; Velazquez-Campoy, A.; De la Rosa, M.A.; Diaz-Quintana, A. Structural and functional characterization of phosphomimetic mutants of cytochrome $\mathrm{c}$ at threonine 28 and serine 47. Biochim. Et Biophys. Acta 2016. [CrossRef] [PubMed]

54. Luan, Q.; Pan, L.; He, D.; Gong, X.; Zhou, H. SC79, the AKT Activator Protects Cerebral Ischemia in a Rat Model of Ischemia/Reperfusion Injury. Med. Sci. Mon. Int. Med. J. Exp. Clin. Res. 2018, 24, 5391-5397. [CrossRef]

55. Liu, X.; Kiss, G.K.; Mellender, S.J.; Weiss, H.R.; Chi, O.Z. Activation of Akt by SC79 decreased cerebral infarct in early cerebral ischemia-reperfusion despite increased BBB disruption. Neurosci. Lett. 2018, 681, 78-82. [CrossRef] [PubMed]

56. Weiss, H.R.; Chi, O.Z.; Kiss, G.K.; Liu, X.; Damito, S.; Jacinto, E. Akt activation improves microregional oxygen supply/consumption balance after cerebral ischemia-reperfusion. Brain Res. 2018, 1683, 48-54. [CrossRef]

57. Sanderson, T.H.; Wider, J.M.; Lee, I.; Reynolds, C.A.; Liu, J.; Lepore, B.; Tousignant, R.; Bukowski, M.J.; Johnston, H.; Fite, A.; et al. Publisher Correction: Inhibitory modulation of cytochrome c oxidase activity with specific near-infrared light wavelengths attenuates brain ischemia/reperfusion injury. Sci. Rep. 2018, 8, 6729. [CrossRef]

58. Strubakos, C.D.; Malik, M.; Wider, J.M.; Lee, I.; Reynolds, C.A.; Mitsias, P.; Przyklenk, K.; Huttemann, M.; Sanderson, T.H. Non-invasive treatment with near-infrared light: A novel mechanisms-based strategy that evokes sustained reduction in brain injury after stroke. J. Cereb. Blood Flow Metab. 2020, 40, 833-844. [CrossRef]

(C) 2020 by the authors. Licensee MDPI, Basel, Switzerland. This article is an open access article distributed under the terms and conditions of the Creative Commons Attribution (CC BY) license (http://creativecommons.org/licenses/by/4.0/). 